\title{
Risk factors for additional port insertion in single-port laparoscopic appendectomy
}

\author{
Kwang Woo Choi ${ }^{1}$, Byung Kwan Park ${ }^{1}$, Suk-Won Suh ${ }^{1}$, Eun Sun Lee ${ }^{2}$, Seung Eun Lee ${ }^{1}$, Joong-Min Park ${ }^{1}$, \\ Yoo Shin $\mathrm{Choi}^{1}$, Beom Gyu Kim ${ }^{1}$, Yong Gum Park ${ }^{1}$ \\ ${ }^{1}$ Department of Surgery, Chung-Ang University College of Medicine, Seoul, South Korea \\ ${ }^{2}$ Department of Radiology, Chung-Ang University College of Medicine, Seoul, South Korea
}

Videosurgery Miniinv 2019; 14 (2): 223-228

DOI: https://doi.org/10.5114/wiitm.2018.77714

\begin{abstract}
Introduction: Single-port laparoscopic appendectomy (SPLA) was expected to have reduced risk of wound infection, less postoperative pain, and improved patient's satisfaction with better cosmesis compared with conventional laparoscopic appendectomy (CLA). When SPLA is converted to CLA, the additional incision for another port insertion can lead to a decrease in the surgical advantages and clinical benefit.

Aim: To evaluate risk factors for conversion to CLA during SPLA.

Material and methods: Between August 2015 and December 2016, patients who underwent intended SPLA were retrospectively reviewed. Conversion was defined as any insertion of an additional port, and complicated appendicitis was defined as gangrenous or perforated appendicitis, abscess, or peritonitis in preoperative computed tomography. Postoperative complication was defined as any deviation in the routine postoperative course within 30 days postoperatively.

Results: Of 409 patients, 65 (15.9\%) were treated with additional port insertion. The overall complication rate was $1.5 \%$ in each group, of which 1 patient developed superficial SSI and 4 patients developed deep surgical site infections in the SPLA group. After univariable and multivariable analysis, old age, male sex, increased serum C-reactive protein (OR = 2.944; 95\% Cl: 1.433-6.047; $p=0.003)$, and complicated appendicitis (OR = 3.330; 95\% Cl: $1.304-$ 8.503; $p=0.012$ ) were significant risk factors for conversion to CLA.

Conclusions: The conversion rate to CLA was 15.9\%. Serum C-reactive protein level and complicated appendicitis were strong predictive factors for conversion from SPLA in acute appendicitis.
\end{abstract}

Key words: appendectomy, risk factors, laparoscopy, appendicitis, single port, conversion.

\section{Introduction}

Laparoscopic appendectomy has been recognized as the gold standard for treatment of acute appendicitis. Numerous studies have reported that laparoscopic appendectomy provides better cosmetic benefits, less postoperative pain, and short recovery time compared with open appendectomy [1-3]. According to the development of minimally invasive surgery, single-port laparoscopic appendectomy (SPLA) has been widely adopted. Compared with conventional laparoscopic appendectomy (CLA), it was expected to have reduced risk of wound infection due to fewer port sites, faster recovery, less postoperative pain, and improved patient's satisfaction with better cosmesis because of a single wound site. Numerous institutions have also reported its safety and feasibility including

\section{Address for correspondence}

Byung Kwan Park MD, Department of Surgery, Chung-Ang University College of Medicine, 102 Heukseok-Ro, Dongjak-Gu, Seoul,

South Korea, phone: +82-2-6299-1559, fax:+82-2-6299-2064, e-mail: headlet@cau.ac.kr 
many studies comparing SPLA with CLA using multiple ports [4-7].

Despite advances in laparoscopic surgical techniques, several factors are required to convert SPLA to CLA $[7,8]$. The suggested reasons for conversion were technical difficulty including adhesion, retroperitoneal location of the appendix, bleeding, and stump amputation [8]. When SPLA is converted to CLA, the additional incision for another port insertion can lead to a decrease in the surgical advantages and clinical benefit. However, there are few data and studies on the risk of conversion or port addition in SPLA, and no definite indication criteria for SPLA application have been established.

\section{Aim}

The aim of this study was to evaluate the risk factors for conversion to CLA from SPLA in acute appendicitis.

\section{Material and methods}

All of the patients who were diagnosed with acute appendicitis underwent attempted SPLA in ChungAng University Hospital. Between August 2015 and December 2016, a total of 409 consecutive patients who were diagnosed with acute appendicitis and initially underwent SPLA were included in this study. This study was reviewed and approved by the institutional review board committee of the Chung-Ang University Hospital (IRB No. 1708-002-16087).

Laparoscopic appendectomy was initially performed by umbilical single-port procedure using a glove port (Nelis, Bucheon, Korea) documented in a previous report [9]. Under the pneumoperitoneum with intra-abdominal pressure of $12 \mathrm{~mm} \mathrm{Hg}, 5-\mathrm{mm}$ straight and $30^{\circ}$-angled laparoscopes were used. The appendiceal base was ligated with 2 applications of Vicryl Endoloop. When inflammation was present at the appendiceal base, cecectomy was performed using a linear stapler (Endo GIA; Medtronic, Seoul, Korea) according to the intraoperative decision of the operator. Conversion to CLA was defined as any additional port insertion during SPLA [10]. The use of antibiotics in our institution was described in a previous study [11].

The clinical characteristics including age, sex, American Society of Anesthesiologists score, body mass index, underlying comorbidities, previous $a b-$ dominal surgery, preoperative laboratory results, and perioperative data were retrospectively reviewed. Complicated appendicitis was defined as gangrenous or perforated appendicitis or if abscess formation was found in the preoperative image, regardless of the presence of fluid collection [10]. Postoperative complication was defined as any deviation in the routine postoperative course within 30 days postoperatively. Patients who had surgical site infections (SSIs) were classified into two groups according to the guideline from the Centers for Disease Control and Prevention: superficial SSI and organ/space SSI [12]. All postoperative intra-abdominal abscesses were included as organ/space SSIs.

\section{Statistical analysis}

Continuous variables were reported as mean and standard deviation. Non-continuous variables were reported as numbers and frequencies. To evaluate the risk factors for conversion to CLA, differences in clinicopathologic characteristics were evaluated between the two groups (SPLA and conversion group) using the $\chi^{2}$ test, Fisher's exact test, and Student's $t$-test, depending on the nature of the variables. In multivariable analysis, binary logistic regression analysis was used for variables with $p$-values $<0.05$ on univariate analysis. All statistical analyses were performed using SPSS software (version 20.0, SPSS, Inc., Chicago, IL, United States).

\section{Results}

Of 409 patients who were initially treated with SPLA for acute appendicitis, 65 (15.9\%) underwent laparoscopic appendectomy with additional port insertion. There was no case converted to open surgery. The reasons for additional port insertion were the following: severe inflammation in 59 (90.8\%) patients, adhesion in $3(4.6 \%)$ patients, and extended surgery in $3(4.6 \%)$ patients. Age, sex, body mass index, underlying comorbidities, and complicated appendicitis were different between the SPLA and conversion groups (Table I). Single-port laparoscopic appendectomy was often performed in younger and female patients ( $75.0 \%$ vs. $56.1 \%$, respectively). In terms of preoperative laboratory results, lymphocyte count and C-reactive protein level were significantly higher in the SPLA group.

Table II presents the operative data and surgical outcome between the SPLA and conversion groups. Cecectomy and colectomy were usually performed 
Table I. Clinical characteristics between the SPLA and conversion groups

\begin{tabular}{|c|c|c|c|}
\hline Characteristics & $\begin{array}{c}\text { SPLA } \\
(n=344)\end{array}$ & $\begin{array}{l}\text { Conversion } \\
(n=65)\end{array}$ & $P$-value \\
\hline Age, mean \pm SD [years]: & $29.0 \pm 16.4$ & $40.8 \pm 21.3$ & $<0.001$ \\
\hline$<40, n(\%)$ & $258(75.0)$ & $35(53.8)$ & 0.001 \\
\hline$\geq 40, n(\%)$ & $86(25.0)$ & $30(46.2)$ & \\
\hline Sex, $n(\%):$ & & & 0.004 \\
\hline Male & $151(43.9)$ & $41(63.1)$ & \\
\hline Female & $193(56.1)$ & $24(36.9)$ & \\
\hline ASA, $n(\%):$ & & & $0.067^{*}$ \\
\hline 1,2 & $343(99.7)$ & $63(96.9)$ & \\
\hline$\geq 3$ & $1(0.3)$ & $2(3.1)$ & \\
\hline BMI, $n(\%):$ & & & 0.004 \\
\hline$<25 \mathrm{~kg} / \mathrm{m}^{2}$ & $278(80.8)$ & $42(64.6)$ & \\
\hline$\geq 25 \mathrm{~kg} / \mathrm{m}^{2}$ & $66(19.2)$ & $23(35.4)$ & \\
\hline Underlying comorbidities, $n(\%)$ : & & & $<0.001$ \\
\hline No & $249(72.4)$ & $30(46.2)$ & \\
\hline Yes & $95(27.6)$ & $35(53.8)$ & \\
\hline Previous laparotomy, $n$ (\%): & & & 0.929 \\
\hline No & $303(88.1)$ & $57(87.7)$ & \\
\hline Yes & $41(11.9)$ & $8(12.3)$ & \\
\hline Delayed appendectomy, $n$ (\%): & & & $0.308^{*}$ \\
\hline No & $339(98.5)$ & $63(96.9)$ & \\
\hline Yes & $5(1.5)$ & $2(3.1)$ & \\
\hline Complicated appendicitis, $n(\%)$ : & & & $0.001^{*}$ \\
\hline No & $330(95.9)$ & $54(83.1)$ & \\
\hline Yes & $14(4.1)$ & $11(16.9)$ & \\
\hline$W B C$, mean $\pm S D[/ \mu l]:$ & $12472 \pm 4112$ & $12409 \pm 4271$ & 0.911 \\
\hline$<10000 / \mu l, n(\%)$ & $90(26.2)$ & $20(30.8)$ & 0.442 \\
\hline$\geq 10000 / \mu l, n(\%)$ & $254(73.8)$ & $45(69.2)$ & \\
\hline Segment neutrophil, mean \pm SD $[/ \mu \mathrm{l}]^{\dagger}$ & $9805 \pm 4074$ & $9969 \pm 4339$ & 0.768 \\
\hline Lymphocyte, mean \pm SD $[/ \mu l]$ & $1818 \pm 791$ & $1597 \pm 685$ & 0.036 \\
\hline Hemoglobin, mean $\pm \mathrm{SD}[\mathrm{g} / \mathrm{dl}]$ & $13.7 \pm 1.6$ & $13.9 \pm 1.6$ & 0.413 \\
\hline Platelet, mean \pm SD $\left[10^{3} / \mu \mathrm{l}\right]$ & $259 \pm 65$ & $241 \pm 74$ & 0.042 \\
\hline C-reactive protein, mean $\pm \mathrm{SD}[\mathrm{mg} / \mathrm{l}]^{\ddagger}:$ & $21.0 \pm 36.7$ & $57.0 \pm 65.1$ & $<0.001$ \\
\hline$<5 \mathrm{mg} / \mathrm{l}, n(\%)$ & $151(43.9)$ & $11(16.9)$ & $<0.001$ \\
\hline$\geq 5 \mathrm{mg} / \mathrm{l}, n(\%)$ & $190(55.2)$ & $53(81.5)$ & \\
\hline
\end{tabular}

${ }^{*}$ Fisher's exact test, ${ }^{\dagger} 1$ case was missing, ${ }^{\dagger} 4$ cases were missing. SPLA - single-port laparoscopic appendectomy, ASA - American Society of Anesthesiologists, $B M I$ - body mass index, WBC - white blood cells. 
Table II. Operative data and surgical outcomes between the SPLA and conversion groups

\begin{tabular}{|c|c|c|c|}
\hline Characteristics & $\begin{array}{c}\text { SPLA } \\
(n=344)\end{array}$ & $\begin{array}{l}\text { Conversion } \\
(n=65)\end{array}$ & $P$-value \\
\hline Operator, $n(\%)$ : & & & $<0.001$ \\
\hline Staff & $248(72.1)$ & $61(93.8)$ & \\
\hline Resident & $96(27.9)$ & $4(4.0)$ & \\
\hline Name of operation, $n(\%)$ : & & & $<0.001$ \\
\hline Appendectomy & $268(77.9)$ & $10(15.4)$ & \\
\hline Cecectomy & $76(22.1)$ & $54(83.1)$ & \\
\hline Colectomy & $0(0.0)$ & $1(1.5)$ & \\
\hline Combined resection, $n(\%)$ : & & & $0.120^{*}$ \\
\hline No & $342(99.4)$ & $63(96.9)$ & \\
\hline Yes & $2(0.6)$ & $2(3.1)$ & \\
\hline Pathologic result, $n(\%)$ : & & & $<0.001$ \\
\hline Acute appendicitis & $213(61.9)$ & $12(18.5)$ & \\
\hline Perforated appendicitis & $126(36.6)$ & $47(72.3)$ & \\
\hline Periappendiceal abscess formation & $4(1.2)$ & $5(7.7)$ & \\
\hline Others & $1(0.3)$ & $1(1.5)$ & \\
\hline Complication, $n(\%)$ : & & & $1.000^{*}$ \\
\hline No & $339(98.5)$ & $64(98.5)$ & \\
\hline Yes: & $5(1.5)$ & $1(1.5)$ & \\
\hline Superficial SSI & 1 & 0 & \\
\hline Deep SSI & 4 & 1 & \\
\hline Duration of operation, mean \pm SD [min] & $43.3 \pm 13.5$ & $73.5 \pm 31.2$ & $<0.001$ \\
\hline Estimated blood loss, mean \pm SD [ml] & $19.4 \pm 9.4$ & $56.2 \pm 104.5$ & $<0.001$ \\
\hline Postoperative hospital stay, mean \pm SD [day] & $2.7 \pm 3.2$ & $5.8 \pm 5.6$ & $<0.001$ \\
\hline
\end{tabular}

${ }^{*}$ Fisher's exact test. SPLA - single-port laparoscopic appendectomy, SSI - surgical site infection.

in the conversion group. The overall complication rate was $1.5 \%$ in each group, of which 1 patient developed superficial SSI and 4 patients developed deep SSI in the SPLA group. The patients who had deep SSI in the conversion group needed intensive care unit admission. There was no mortality 30 days postoperatively in each group. The duration of the operation, amount of estimated blood loss, and postoperative hospital stay were significantly longer in the conversion group.

In the multivariate analysis model with the significant variables in the univariate analysis, old age (OR = 1.031; 95\% Cl: 1.014-1.049; $p<0.001)$, male sex (OR
$=2.119 ; 95 \% \mathrm{Cl}: 1.131-3.971 ; p=0.019)$, increased serum $C$-reactive protein level $(O R=2.944 ; 95 \% \mathrm{Cl}$ : 1.433-6.047; $p=0.003)$, and complicated appendicitis $(\mathrm{OR}=3.330 ; 95 \% \mathrm{Cl}: 1.304-8.503 ; p=0.012)$ were significant risk factors for conversion to CLA (Table III).

\section{Discussion}

This study successfully determined the risk factors for conversion to CLA. There are many studies about the comparison between SPLA and CLA. However, there are few studies about conversion risk factors. Our study is unique in this light and demonstrated that severe inflammation (C-reactive protein 
Table III. Multivariable analysis of predictive risk factors for conversion to CLA

\begin{tabular}{|lccc|}
\hline Variables & Odds ratio & 95\% confidence interval & $P$-value \\
\hline Age & 1.031 & $1.014-1.049$ & $<0.001$ \\
\hline Male & 2.119 & $1.131-3.971$ & 0.019 \\
\hline Body mass index $\geq 25 \mathrm{~kg} / \mathrm{m}^{2}$ & 1.410 & $0.727-2.733$ & 0.309 \\
\hline Lymphocyte & 1.000 & $0.999-1.000$ & 0.101 \\
\hline Platelet & 1.001 & $0.996-1.006$ & 0.788 \\
\hline C-reactive protein $\geq 5 \mathrm{mg} / \mathrm{l}$ & 2.944 & $1.433-6.047$ & 0.003 \\
\hline Complicated appendicitis & 3.330 & $1.304-8.503$ & 0.012 \\
\hline
\end{tabular}

CLA - conventional laparoscopic appendectomy.

and complicated appendicitis) could be a significant risk factor.

C-reactive protein is well known as one of the acute-phase inflammatory proteins [13]. Increased serum C-reactive protein level suggested more intense local inflammatory reaction and severe appendicitis. Increased serum C-reactive protein level has also been reported as a risk factor for conversion to open surgery during laparoscopic appendectomy [14]. In this study, complicated appendicitis was defined as gangrenous or perforated appendicitis. As inflammation proceeded in acute appendicitis, the tissue became edematous and friable with increasing risk of bleeding, and adhesion with the surrounding tissue developed. Studies have reported that complicated appendicitis was a risk factor for conversion to laparotomy in laparoscopic appendectomy [14-16].

Single-port laparoscopic appendectomy has several technical issues. Triangulation with multiple instruments is difficult, and maintenance of the traction-countertraction of the target organ is challenging due to parallel entry of straight instruments and the occasional collision between handles of different instruments [10]. These basic technical issues and severe inflammation might increase the possibility of additional port insertion. In this study, appendectomy was often performed and more perforated appendicitis and abscess formation were identified in the conversion group than the SPLA group. Moreover, the operation time and amount of blood loss were also significantly longer and greater, respectively, in the conversion group.

As seen in previous studies on single-incision operations, the transumbilical single-incision approach is feasible and safe, and there is no greater incidence of complications $[4,17,18]$. One of the advantages of the single-port approach was greater comfort and less pain for patients. This might be achieved by reducing the size of the skin incision and not perforating the aponeurosis in the muscle. The umbilicus, located in the thinnest part of the abdominal wall, makes it easier to insert the multi-entry port, move in all directions, and then close the orifice under direct vision to avoid the possibilities of incisional hernia.

Male sex and old age were the significant risk factors of this study. There are studies reporting that male sex and old age were independent predictive factors for open conversion in laparoscopic appendectomy [14, 15, 19]. Gupta et al. reported that several risk factors including old age, male sex, longer duration of symptoms, and severe inflammation in computed tomography scan were present in combination [16]. In real practice, the operator might have a tendency to keep on performing single-port surgery in young female patients for cosmetic reasons. Moreover, older male patients tend to think that when they first experience abdominal pain, they are more likely to endure abdominal pain than younger women. Therefore, the delayed diagnosis was possible to associate with severe inflammation and conversion to CLA.

In this study, the overall rate of conversion to CLA was $15.9 \%$. Several randomized trials concerning SPLA have reported rates of $8.2-11.1 \%$ for additional port insertion [7, 8, 20]. Because our institution was a tertiary referral center and teaching hospital, the overall conversion rate of this study was higher than those of other trials. The staff surgeon performed more conversions to CLA. It means that the resident performed SPLA in relatively easier cases, and the operator was replaced with a staff surgeon in difficult cases.

Obesity has been considered as a difficulty in laparoscopic surgery. However, body mass index was 
not a risk factor for conversion to CLA in this study. The bulky mesenteric fat itself did not seem to interfere with the operation field because the appendix located on the right lower quadrant can be easily exposed by a position change of patients. This study indicates that severe inflammation rather than obesity influences the difficulty in completion of SPLA.

The limitation of this study was its retrospective nature. The postoperative complications of this cohort might have been underestimated because our institution had the policy that patients are required to be followed up only once, 1 week after discharge. The rate of complicated appendicitis was lower than that in another large cohort study [21]. Our institution is a tertiary referral center from other clinics, and patients were referred from other clinics with low quality images (CT or USG). Also, ambiguous microperforation that is suspicious discontinuity of appendiceal mucosa and tiny periappendiceal fat stranding might be missed. This study was conducted on a small, single-center, retrospective cohort. Several variables including laboratory results were missing.

\section{Conclusions}

Many patients with acute appendicitis are able to undergo SPLA. However, some of them also require conversion to CLA with additional ports. In our study, the conversion rate to CLA was $15.9 \%$. Furthermore, increased serum CRP level and complicated appendicitis were strong predictive factors for conversion to CLA from SPLA in acute appendicitis.

\section{Conflict of interest}

The authors declare no conflict of interest.

\section{References}

1. Wei HB, Huang JL, Zheng ZH, et al. Laparoscopic versus open appendectomy: a prospective randomized comparison. Surg Endosc 2010; 24: 266-9.

2. Lujan Mompean JA, Robles Campos R, Parrilla Paricio P, et al. Laparoscopic versus open appendicectomy: a prospective as sessment. Br J Surg 1994; 81: 133-5.

3. Page AJ, Pollock JD, Perez S, et al. Laparoscopic versus open appendectomy: an analysis of outcomes in 17,199 patients using ACS/NSQIP. J Gastrointest Surg 2010; 14: 1955-62.

4. Frutos MD, Abrisqueta J, Lujan J, et al. Randomized prospective study to compare laparoscopic appendectomy versus umbilical single-incision appendectomy. Ann Surg 2013; 257: 413-8.

5. Kim SJ, Choi BJ, Jeong W, et al. The feasibility of single-port laparoscopic appendectomy using a solo approach: a comparative study. Ann Surg Treat Res 2016; 90: 164-70.
6. Xu AM, Huang L, Li TJ. Single-incision versus three-port laparoscopic appendectomy for acute app endicitis: systematic review and meta-analysis of randomized controlled trials. Surg Endosc 2015; 29: 822-43.

7. Teoh AY, Chiu PW, Wong TC, et al. A double-blinded randomized controlled trial of laparoendoscopic single-site access versus conventional 3-port appendectomy. Ann Surg 2012; 256: 909-14.

8. Kang BM, Choi SI, Kim BS, et al. Single-port laparoscopic surgery in uncomplicated acute appendicitis: a randomized controlled trial. Surg Endosc 2018; 32: 3131-7.

9. Lee SE, Choi YS, Kim BG, et al. Single port laparoscopic appendectomy in children using glove port and conventional rigid instruments. Ann Surg Treat Res 2014; 86: 35-8.

10. Kang BM, Hwang JW, Ryu BY. Single-port laparoscopic surgery in acute appendicitis: retrospective comparative analysis for 618 patients. Surg Endosc 2016; 30: 4968-75.

11. Song DW, Park BK, Suh SW, et al. Bacterial culture and antibiotic susceptibility in patients with acute appendicitis. Int J Colorectal Dis 2018; 33: 441-7.

12. Mangram AJ, Horan TC, Pearson ML, et al. Guideline for Prevention of Surgical Site Infection, 1999. Centers for Disease Control and Prevention (CDC) Hospital Infection Control Practices Advisory Committee. Am J Infect Control 1999; 27: 97-132.

13. Pepys MB, Baltz ML. Acute phase proteins with special reference to C-reactive protein and related proteins (pentaxins) and serum amyloid A protein. Adv Immunol 1983; 34: 141-212.

14. Abe T, Nagaie T, Miyazaki M, et al. Risk factors of converting to laparotomy in laparoscopic appendectomy for acute appendicitis. Clin Exp Gastroenterol 2013; 6: 109-14.

15. Finnerty BM, Wu X, Giambrone GP, et al. Conversion-to-open in laparoscopic appendectomy: a cohort analysis of risk factors and outcomes. Int J Surg 2017; 40: 169-75.

16. Gupta N, Machado-Aranda D, Bennett K, et al. Identification of preoperative risk factors associated with the conversion of laparoscopic to open appendectomies. Int Surg 2013; 98: 334-9.

17. Buckley FP $3^{\text {rd }}$, Vassaur H, Monsivais S, et al. Single-incision laparoscopic appendectomy versus traditional three-port laparoscopic appendectomy: an analysis of outcomes at a single institution. Surg Endosc 2014; 28: 626-30.

18. Teoh AY, Chiu PW, Wong TC, et al. A case-controlled comparison of single-site access versus conventional three-port laparoscopic appendectomy. Surg Endosc 2011; 25: 1415-9.

19. Wagner PL, Eachempati SR, Aronova A, et al. Contemporary predictors of conversion from laparoscopic to open appendectomy. Surg Infect (Larchmt) 2011; 12: 261-6.

20. Lee WS, Choi ST, Lee JN, et al. Single-port laparoscopic appendectomy versus conventional laparoscopic appendectomy: a prospective randomized controlled study. Ann Surg 2013; 257: 214-8.

21. Lasek A, Pędziwiatr M, Wysocki M, et al. Risk factors for intraabdominal abscess formation after laparoscopic appendectomy - results from the Pol-LA (Polish Laparoscopic Appendectomy) multicenter large cohort study. Videosurgery Miniinv 2018 DOI: https://doi.org/10.5114/wiitm.2018.77272.

Received: 10.07.2018, accepted: 6.08.2018. 